\title{
Attributes, challenges and future directions of community resilience
}

(C) The Author(s) 2018. Published by Higher Education Press. This is an open access article under the CC BY license (http:// creativecommons.org/licenses/by/4.0)

\begin{abstract}
With the continuous development of human society, the damage to the natural environment is becoming increasingly large, causing crisis events to occur frequently. In recent years, the study of community resilience is becoming popular among scholars because of its perspective on disaster prevention and mitigation. In this study, we apply database retrieval to untangle community resilience-related papers from multiple directions. We analyze the connotation, attribute, and composition of community, resilience, and community resilience comprehensively by summarizing important issues and research progress in community resilience. Challenges and shortcomings faced by community resilience development are also determined. Moreover, we put forward the research directions that future research can focus on. Through literature review, current research on community resilience focuses on the following aspects: "infrastructure construction," "crowd in the community," "economic resilience," "social capital," and "measurement of community resilience." Such research is not yet systematic and relatively decentralized. The attention to collective resilience in the community is relatively weak, which makes achieving the goal of "people-oriented and systematic control" difficult. Therefore, this study states that the development of future
\end{abstract}

Received March 24, 2018; accepted May 25, 2018

Bo MENG, Nan LI, Dongping FANG ( $($ )

Department of Construction Management, West Main Building, Tsinghua University, Beijing 100084, China

E-mail: fangdp@tsinghua.edu.cn

This work was funded by the National Key R\&D Program of China (Grant No. 2017YFC0803308), Humanities and Social Science Foundation of the Ministry of Education of China (Grant No.13YJCZH129), National Natural Science Foundation of China (Grant Nos. U1709212, 71741023 and 71741025), and Tsinghua University Initiative Scientific Research Program (Grant Nos. 2014z21050 and 2015THZ0). community resilience should stand from the perspective of "system of system" and build on knowledge and tools of various relevant domains. Therefore, public needs and participation are highlighted as breakthrough points. The research should integrate infrastructure and economic resilience, social resource allocation, network connection, and other aspects to build a holistic and functional resilient community.

Keywords community resilience, literature analysis, resilience attribute, social resource, future direction

\section{Introduction}

In the past decades, community resilience, as a popular concept, has gained increasing attention from the academic and professional world. Researchers, strategy planners, community activists, and development practitioners all play important roles in developing this concept (Abramson et al., 2015). Various research efforts on resilience have been carried out. Given the wide and rapid effect and disturbance around the world (IFRC, 2015), such as the authoritarian political system, military invasion, global economic downturn, threat of global climate change, and environmental disasters (Rogers et al., 2012), resilience has become one of the most ideal paradigms dealing with community uncertainty as well as disaster risk prediction and prevention.

Many studies are still discussing the concept of "resilience," but such concept and definition are diverse. Experts and scholars' opinions are also divergent on these two issues: "How does it form resilience"? and "What resilience does it form"? Psychologists focus on how individuals face the impacts of the outside world, whereas engineers pay attention to the resilience of buildings before and after disasters (Wisner and Kelman, 2015). The concept of resilience and related research are evidently cross-disciplinary, including natural science, psychology, and social science. Therefore, studying resilience from a 
single perspective is limited. However, standing in the angle of the system to grasp the exact attribute of resilience is accurate. Research results should be of many disciplines to discuss the opportunities and challenges of resilience. The main objective of this study is to provide the concept, connotation, attributes, and measurement methods of community resilience from multiple perspectives, through the analysis of relevant studies. We focus on the problems, which must be solved in community construction, especially the key problems on disaster resilience, which still exists after disasters.

\section{Research method}

We focus on the resilience under the circumstance of disaster risk events. Thus, studies searched are in the field of disaster risk. We analyze a systematic review of trends of community resilience, and we focus on the following points.

- relevant concepts of community resilience;

- attribute and connotation of community resilience;

- measurement of community resilience; and

- composition of community resilience.

We quote the analysis results and discuss the problems as well as the future of community resilience development through relevant relations.
Community resilience is a multi-dimensional concept. Thus, interdisciplinary search method is applied to identify relevant literature. The goal of the search is to summarize community resilience-related papers in disaster risk areas. The literature search consists of two main databases: Web of Science and Engineering Village. Collected papers from Web of Science involve multiple disciplines, such as physics, engineering, life, health, social, and humanity science, which are important parts of community resilience. Engineering Village database contains several engineering papers. The combination of keywords used in the retrieval process are "community," "resilience," "disaster," "hazard," "infrastructure," "assessment," "citizen," "conception," and "component." Boolean symbols are used to retrieve literature and academic studies related to "community resilience" between 1990 and 2017.

Regarding the choice of keywords, "community" and "resilience" are the core words of our study. We focus on community resilience regarding disaster risks. Thus, "hazard" and "disaster" are also used interchangeably in the retrieval process. In the retrieval results, we focus on high impact and citation frequency articles as well as trending topics in related research. By analyzing these articles, we further define the key points of this paper. The words "infrastructure," "assessment," "citizen," "conception," and "component" are selected as keywords of quadratic search. The retrieval results are shown below.

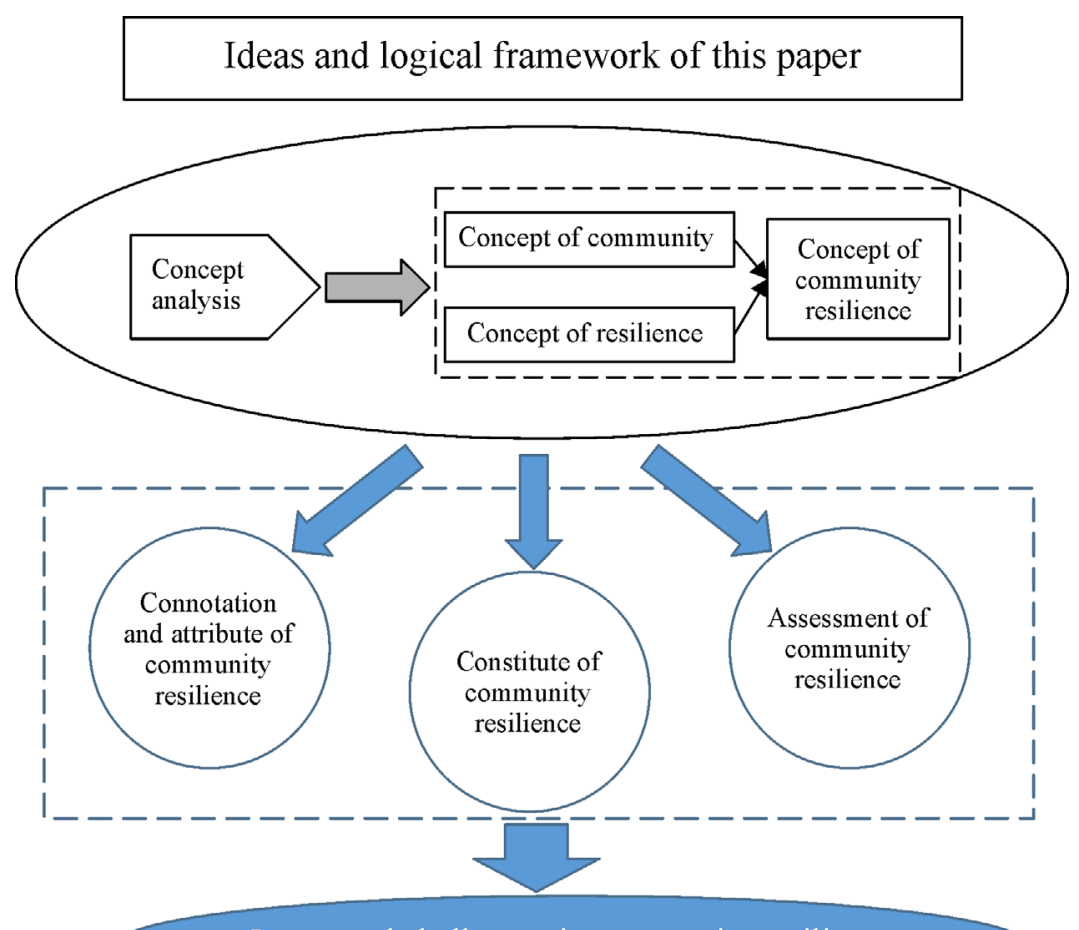

Issues and challenges in community resilience

Fig. 1 General idea and logical framework 
Table 1 Statistical results of literature retrieval

\begin{tabular}{|c|c|c|c|}
\hline Number & Key words & Quantity & Journal name and percentage \\
\hline \multirow[t]{8}{*}{1} & \multirow{8}{*}{$\begin{array}{c}\text { Community }+ \\
\text { resilience }+ \\
\text { disaster or hazard } \\
\quad+\text { citizen }\end{array}$} & \multirow[t]{8}{*}{90} & Natural Hazards $(7.78 \%)$ \\
\hline & & & International Journal of Disaster Risk Reduction (3.33\%) \\
\hline & & & Disaster Medicine and Public Health Preparedness (3.33\%) \\
\hline & & & Procedia Economics and Finance (2.22\%) \\
\hline & & & Natural Hazards and Earth System Sciences $(2.22 \%)$ \\
\hline & & & Journal of Korea Institute of Information Electronics and Communication Technology (2.22\%) \\
\hline & & & Ecology and Society $(2.22 \%)$ \\
\hline & & & Disaster Prevention and Management $(2.22 \%)$ \\
\hline \multirow[t]{9}{*}{2} & \multirow{9}{*}{$\begin{array}{l}\text { Community }+ \\
\text { resilience }+ \\
\text { disaster or hazard } \\
\quad+\text { concept }\end{array}$} & \multirow{9}{*}{351} & Natural Hazards $(6.83 \%)$ \\
\hline & & & International Journal of Disaster Risk Reduction (4.274\%) \\
\hline & & & Prehospital and Disaster Medicine (2.78\%) \\
\hline & & & Disaster Medicine and Public Health Preparedness (1.99\%) \\
\hline & & & Global Environmental Change Human and Policy Dimensions (1.71\%) \\
\hline & & & International Journal of Disaster Risk Science (1.42\%) \\
\hline & & & Journal of Public Health Management and Practice (1.42\%) \\
\hline & & & Natural Hazards and Earth System Sciences $(1.42 \%)$ \\
\hline & & & Science of The Total Environment (1.42\%) \\
\hline \multirow[t]{9}{*}{3} & \multirow{9}{*}{$\begin{array}{l}\text { Community }+ \\
\text { resilience }+ \\
\text { disaster or hazard } \\
+ \text { component }\end{array}$} & \multirow{9}{*}{155} & International Journal of Disaster Risk Reduction (5.16\%) \\
\hline & & & Natural Hazards (3.87\%) \\
\hline & & & Ecology and Society $(3.22 \%)$ \\
\hline & & & $\begin{array}{c}\text { 4th International Conference on Building Resilience Incorporating the 3rd Annual Conference of the Android } \\
\text { Disaster Resilience Network (2.58\%) }\end{array}$ \\
\hline & & & Journal of Structural Engineering (2.58\%) \\
\hline & & & Procedia Economics and Finance $(2.58 \%)$ \\
\hline & & & Natural Hazards Review (1.94\%) \\
\hline & & & Plos One $(1.94 \%)$ \\
\hline & & & Prehospital and Disaster Medicine (1.94\%) \\
\hline \multirow[t]{9}{*}{4} & \multirow{9}{*}{$\begin{array}{c}\text { Community }+ \\
\text { resilience }+ \\
\text { disaster or hazard } \\
+ \text { infrastructure }\end{array}$} & \multirow[t]{9}{*}{243} & International Journal of Disaster Risk Reduction (3.29\%) \\
\hline & & & $\begin{array}{l}\text { 4th International Conference on Building Resilience Incorporating the 3rd Annual Conference of the Android } \\
\text { Disaster Resilience Network (2.46\%) }\end{array}$ \\
\hline & & & Disaster Medicine and Public Health Preparedness (2.46\%) \\
\hline & & & Natural Hazards $(2.46 \%)$ \\
\hline & & & Procedia Economics and Finance $(2.46 \%)$ \\
\hline & & & Reliability Engineering System Safety $(2.46 \%)$ \\
\hline & & & Journal of Business Continuity Emergency Planning (2.05\%) \\
\hline & & & Journal of Structural Engineering (2.05\%) \\
\hline & & & Natural Hazards and Earth System Sciences (1.65\%) \\
\hline
\end{tabular}

\section{Community, resilience, and community resilience}

3.1 What is community?

The word "community" derives from the old French "comuneté," which comes from the Latin communitas"community," "public spirit" (Matthews, 2014). Wisner and Kelman (2015) stated the term "community" originated in the middle ages from the word "common," representing the meaning of "collectivity," "public," and "common ownership." In academia, the term "community" was first applied in German Social Science Research in the nineteenth century, and then became popular in different fields (Wisner and Kelman, 2015). "Community" is a liquid concept, which represents a social structure. Its main 
concern is regional interest surveys (Sherrieb et al., 2010; Mohan and Stokke, 2000). Community can be regarded as "the unity of sense of belonging," "the functional unit of production and exchange," and "the relation network and collective behavior" (Chaskin, 2008). A community includes community composition (people with certain characteristics living together), regional characteristics (environmental features such as population of living area), and functional components (community function, mechanism, and process) (Sherrieb et al., 2010). Bell and Newby (1973) believes the word "community" has at least 98 different descriptions and extensions. Early studies on "community" found certain people are marginalized and unable to obtain the right to make decisions because of history, race, religion, gender, age, ability, health status, immigration status, sexual preferences, and other reasons. Meanwhile, few individuals gain power, wealth, and information (Wisner and Kelman, 2015). The term is also used to cover exploitation and conflict. The lack of homogeneity in most communities is emphasized, but the term "community" implies consistency (Agrawal and Gibson, 1999; Walmsley, 2006). The definition of "community" is diverse, including the sum of social system interactions, such as affective units and network associations. Community is usually defined as a continuous geographic space (Wilson, 2012a). Any group that has common interests and cultures, mutual recognition, and sharing activities (Fellin, 2001; Ungar, 2011), people who live in an administrative unit (Allen, 2006), and a unit of society gathered by means of benefit and kinship (Murphy, 2007) can be defined as "community." In the context of resilience research, the most important feature of community is that people can identify problems together, make decisions, solve problems, and allocate resources (Dynes, 1998). Community can be scaled from a village to the entire world, but researchers prefer moderate social resilience scale as research object, that is, upon the scale of family and under that of region (Wilson, 2012a). Community can exhibit functional characteristics of different members, including (1) regular interactive activities among community members; (2) interactions which are not dominated by the state; and (3) members who have common preferences or beliefs to certain extent (Flora, 1998).

In this study, "community" represents residents living in a common place. It is a geographical entity with boundaries, and the scales lie between the family and the region. It may not be continuous in space because communities may involve different groups. Moreover, distances between these groups may be far apart, such as immigration community.

\subsection{Understanding resilience}

When the word "resilience" refers to people and surroundings, it is considered as a metaphor (Norris et al., 2008). In the study of physics and mathematics, "resilience" is originally used to describe the capability of materials or systems to restore the original balance after replacement. For example, materials with resilience that bounce back rather than stop when bent (Bodin and Wiman 2004; Gordon, 1978). In physics, resilience neither focuses on the initial displacements nor the magnitude of oscillations but on the speed of returning to steady-state. Images are a compelling means to trigger people's imagination on resilience. Holling (1973) used images to interpret the terms of "ecological resilience" in his influential paper. Since then, the concept of resilience has been used to describe individuals' ability to adapt (Bonanno et al., 2006; Butler et al., 2007; Rutter, 1993; Werner and Smith, 1982), it refers to community (Kulig, 2000; Sonn and Fisher, 1998), and large social groups as well (Adger, 2000; Godschalk, 2003). An increasing number of studies have involved the concept of resilience. However, certain criticisms consider this concept unsuitable, inaccurate, and vague (Bodin and Wiman, 2004; Carpenter et al., 2001; Cowen, 2001; Klein et al., 2003).

In the 20th century, the term "resilience" was increasingly used in medicine, engineering, psychology as well as natural and human ecology. In recent decades, many other disciplines have also developed the concept of "resilience" from the perspective of different disciplines. For example, Manyena and Gaillard explained the concept of "resilience" from the perspective of disaster risk reduction (Manyena, 2006; Gaillard, 2007). Many scholars and organizations have their own understanding of the concept and connotation of "resilience." For example, Turnbull et al. (2013) defined "resilience" as the capability of prediction, absorption, and recovery of individuals, families, and communities. They also defined the word as the ability of not being affected or restrained (or even enhance the ability) by disasters, such as climate change and other impact and pressure caused by harm. The United Nations defines "resilience" as the ability to achieve and maintain acceptable functional and structural levels through resistance or change when a system, community, or society is affected by risk. Increasing the ability to learn from past disasters, improving risk prevention measures, and protecting the future depends on the extent to which social systems can be self-organized (UNISDR, 2014). Rockefeller Foundation describes "resilience" as the "running ability of the city, life, and work of people in city, especially the poor and vulnerable people. No matter what kind of pressure or impact happens, people can survive, and cities can develop" (Alshehri et al., 2015a). Dominelli (2012) considers resilience having certain randomness and is not always a forward linear motion. Resilience can move forward or backward in different statuses such as in the absence of resilience, with sufficient survival resilience, or maintaining a state of resilience prior to disasters. Resilience is transformative. It makes people progress and become better than before. 
Based on the literature review, resilience has two major characteristics. 1) Resilience is more of a capacity or process than a result (Brown and Kulig, 1996; Pfefferbaum et al., 2008); 2) Adaptability is a better interpretation of resilience than stability (Handmer et al., 1999). In certain cases, stability (or no change) may represent lack of resilience. For example, the resilience of systems means one part can respond to change or adapt to other parts. Therefore, if such part remains stable, then systems cannot maintain resilience (Adger, 2000; Klein et al., 2003).

Norris defined resilience as a process which links selfadaptive capabilities and active-adaptive capacities after disasters (Norris et al., 2008). Adaptive capability is a resource with dynamic attributes. The actor of the definition can be divided into different scales, which can be a person, a society, human society, or the entire ecosphere. These definitions of resilience consist essentially of three characteristics, which are absorptive, adaptable, and recovery capacity. Absorptive capacity means that systems can resist impact. Adaptable capacity means changing to meet new demands. Recovery capacity is the returning balance of community and society (Vugrin et al., 2010).

\subsection{What is community resilience?}

The concept of community resilience was first proposed by Judith Kulig and his colleagues at the Alberta health service center in Canada (Kulig, 2000; Reid and Botterill, 2013). Ahmed and Islam argued that social resilience refers to the productive and technological capacity of human society to prevent, combat, or mitigate traumatic events (Ahmed et al., 2004; Isam and Quek, 2014). The challenges faced by communities are perceived as pressures from outside, such as social and political threats or environmental changes (Adger, 2006). Such challenges may also be the result of the fragility of communities' internal evolution process (Kelly and Bliss, 2009b; Davoudi et al., 2012; Wilson, 2012). The concept of "community resilience" also has the problem of "resilience" itself, which is diverse and controversial. The concept is further complicated by the addition of "community" notion (Pfefferbaum et al., 2005). Community is an entity with distinct geographical boundaries and consistency. It is composed of complex natural, social, and economic environments that interact with each other. Norris et al. argued that "community resilience" represents a process that links self-adaptive capability (dynamic attributes of resources) and adaptation to disasters or disturbances (Norris et al., 2008). The adaptability of communities is reflected in the mental and physical health of the people living in it, manifested in a high-level life function and quality. The self-adaptive capacity of community resilience is mainly embodied in four aspects, such as economic development, social capital, information and communication, and community skills. When disasters occur, these four aspects provide strategies for responding to such disasters all together. Community resilience during disasters can be defined as social units (such as organization, community) in harm, taking actions to reduce social chaos, restoring social activities, and mitigating future disasters (Wanitkorkul and Filiatrault, 2005).

By analyzing the concepts, researches about the concept of resilience continues currently, scholars from various disciplines focus on the development of resilience, and the specific concept with the characteristics of their fields of study are discussed. Therefore, the concept of "resilience" is still in dispute and remains as a popular research topic in recent years. Establishing an interdisciplinary concept of resilience under the perspective of system and integrating comprehensive concepts of different disciplines are interesting. We also find the existence of the gradually convergent trend of research. For example, most scholars believe that "adaptability" is one of the core contents of resilience. The majority of scholars think that we should pay more attention on the "process" research of resilience than only pursuing results.

\section{Connotation and attribute of community resilience}

\subsection{Connotation of community resilience}

Khew et al. (2015) believed that community resilience consists of two aspects (Fig. 2). 1) "Soft resilience", which mainly refers to the resilience of the community from the perspective of policy, culture, and spiritual civilization, and 2) "Hard resilience", which mainly focuses on constructing infrastructure as well as defense equipment and facilities.

Handmer and Checkland claimed that resilience can be classified as hard, soft, and hybrid resilience (Handmer and Dovers, 1996; Checkland, 2000).

Hard resilience is descriptive, non-normative (Brand and Jax, 2007; Wiek et al., 2012), tangible, with precise definition. It can also be quantitatively measured (Handmer and Dovers, 1996). Hard resilience shows physical resilience, and the role of which is mainly embodied in the following three aspects.

- To reduce the direct damage of disaster events;

- To start the multi-function system and promote the rapid recovery of the social-economic system after disasters;

- To strengthen the construction of soft resilience by enhancing physical resilience.

Contrary to hard resilience, the main characteristics of soft resilience are vague, ductile, normative, and intangible. Moreover, accomplishing quantitative analysis is difficult. Soft resilience does not have direct protection of cities as well as hard resilience like its resistance to destructive events. The resilience related to human and social systems mostly belongs to soft resilience, including 


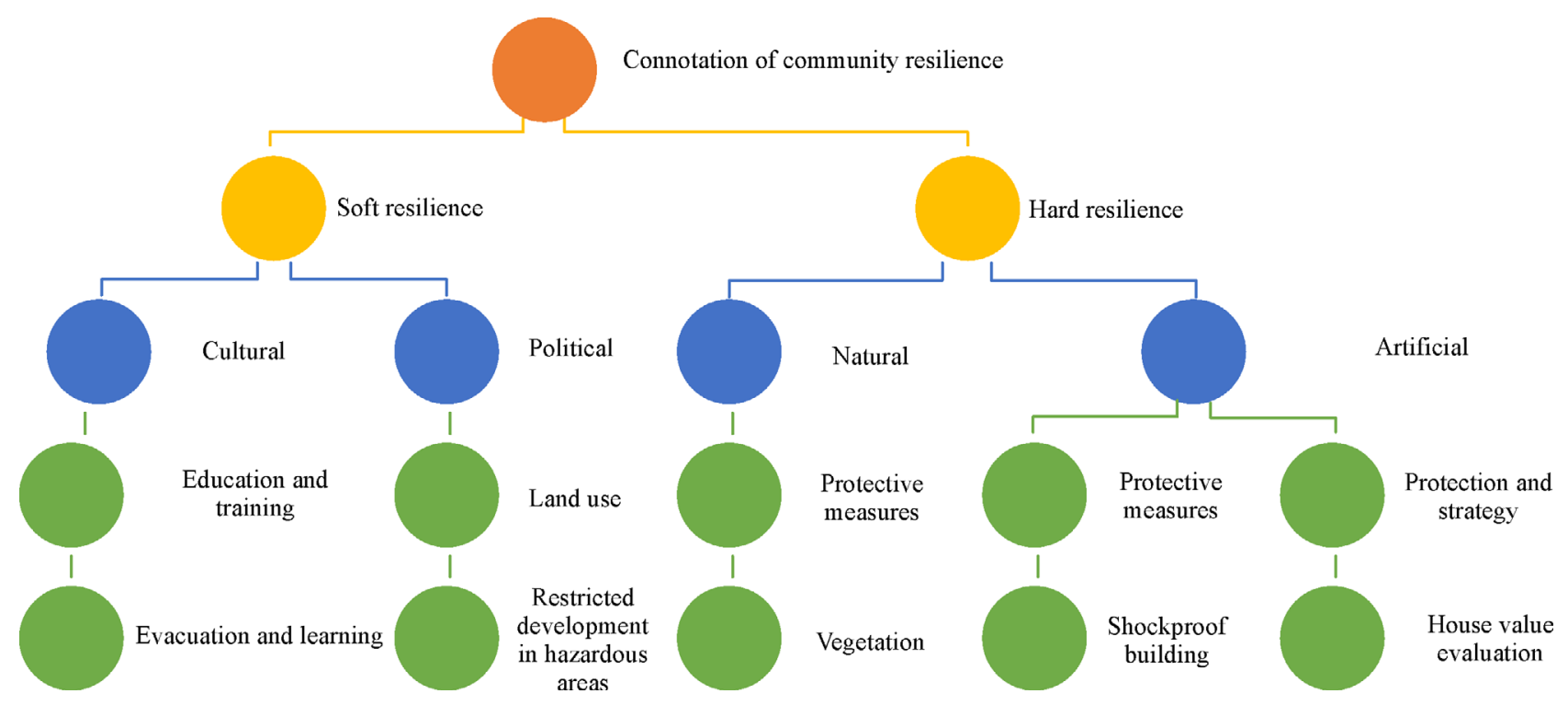

Fig. 2 Connotation of Community Resilience (adapted from Khew et al., 2015)

psychological and economic resilience (Kais and Islam, 2016). Psychological resilience refers to the adaptation capacity of human beings. Psychiatry literature in the early days defined children who can bear high risks as "invulnerable." After a period of evolution, "invulnerable" was replaced by "resilient" (Earvolino-Ramirez, 2007; Reid and Botterill, 2013; Rogers, 2013). Many psychologists defined psychological resilience as the developed personal potential. Individuals not only face and treat pressure and disasters well but also transform pressure or disasters as motivation, obtaining opportunities through learning (Neil, 2015). "Soft resilience" reflects the combination of many social factors, including the management style of decision makers before and after disasters, the health status of people, the consciousness of groups, the sense of self-help, and the level of education of communities.

Hybrid resilience is the third kind of resilience. It is a cross-discipline concept between natural and social science (Brand and Jax, 2007; Wilson, 2012b). Social-ecological and organizational resilience can be cited as two examples of hybrid resilience. The social-ecological resilience system takes human beings as a part of the ecosystem. The nature-culture system is divided into two parts, natural and artificial. Adger defined social-ecological resilience as the capability of social ecosystems to absorb recurrent disturbances to maintain their basic structure, process, and feedback (Adger, 2000, 2003). The organizational resilience of enterprises is another example of hybrid resilience.

\subsection{Attributes of community resilience}

Community resilience includes static and dynamic attri- butes. It can be defined as an intrinsic and existing state (Rose, 2004; Cutter et al., 2008; Islam, 2014). Intrinsic resilience reflects the definition of "resilience ontology," and concerns with the nature of systems (Colten et al., 2008; McCrea et al., 2014). Systems' capabilities to operate under normal conditions and to recover from crises are some examples (Cutter et al., 2008). Intrinsic resilience can be considered as a snapshot of a static state, which is a potential attribute of systems (Ahmed et al., 2004; Islam and Quek, 2014). The resilience of systems also represents the quality of the "self-adaption," which is a process in and after crises. At this scale, attention should be paid on "what systems are going to be" (Colten et al., 2008) and "what systems are doing" (McCrea et al., 2014). From this point of view, resilience is no longer a fixed attribute of systems but shows the flexibility in responding to disasters. The initial structure or function of systems may experience necessary changes. Thus, resilience should be regarded as "a quality, a character, or a result" (Manyena, 2006). Handmer and Dovers considered the results and processes of resilience as the passivity and activity of resilience, respectively (Handmer and Dovers, 1996). For passive resilience, constant stability is crucial (Dovers and Handmer, 1992). However, active resilience represents the acceptance of the inevitability of changes and attempts to create new systems that can adapt to new conditions and requirements (Handmer and Dovers, 1996). Static and dynamic resilience lead to different community resilience construction projects. For example, resilience projects that are result-oriented focus on "management and command patterns," with the goal of returning to the original society state. Resilience projects that are process-oriented focus on the conduct of community through a series of evolving behaviors over time. 


\section{Components of community resilience}

Many areas have proposed the definition of resilience. However, several researchers have focused on a core understanding, which is, social resilience is composed of living environment, infrastructure, economy, environment and resources, government management and resistance, and social system adaptability (Romero-Lankao, 2010; Satterthwaite and Mitlin, 2013; Jonkeren and Giannopoulos, 2014; Kumaraswamy et al., 2017). When we focus on the resilience of communities at risk, the things we should consider first are individuals and infrastructure. In large cities with modern infrastructure (water, electricity), we should first consider infrastructure to prevent people from suffering and then take care of individuals. If no working infrastructure, such as in rural areas, exists, then any method can be adopted. Aspects other than people may be sacrificed because the survival of humans is the priority in disasters (Aloudat and Christensen, 2012). Infrastructure resilience is becoming increasingly important in the face of climate change and growing urbanization. Infrastructure assets are not only important financial investments but also provide basic social value. Thus, constructing infrastructure resilience becomes the core of the research content. However, resilience itself is abstract and poses many challenges in implementation (Kumaraswamy et al., 2017). At the same time, resilience depends on the available resources in systems, which can help members of the community to cope with disasters. The relationship between abilities and access to resources is systematized (Wisner et al., 2012). Finally, all upper construction requires economic foundation for support. The resilience of economy and economic system, which can recover quickly after disasters, and provide strong support and facilitate the necessary conditions for communities to recover.

Community is a human-based social ecological system, the biggest difference of which from natural ecosystems lies in the following points:

- Human beings are dominant in the system;

- Infrastructure, including lifeline systems and different types of buildings and functional facilities, constitute the main frame of the system;

- Most operations in the system are driven by economy;

- Whether the function of the system can be embodied fully depends mainly on the relationship between human and social resources.

Therefore, this study discusses mainly the components of resilience from the perspectives shown in Fig. 3.

\subsection{Crowd in community resilience}

Communities are an epitome of the typical human ecosystem. The creators of communities are human beings, and their destroyers are human beings, too. Therefore, building community resilience considering human beings as the core object is fundamental.

Many scholars have emphasized the importance of people in community resilience. Campanella proposed in "Urban Resilience and the Recovery of New Orleans" that the city and resilience are attributed to people (Campanella, 2006). The ingenuity of enterprises lies with their employees and management, whereas the resilience of cities lies with their citizens. Based on history, only resilient citizens are competent to build resilient cities. Ranjan and Abenayake (2014) stated that the risk

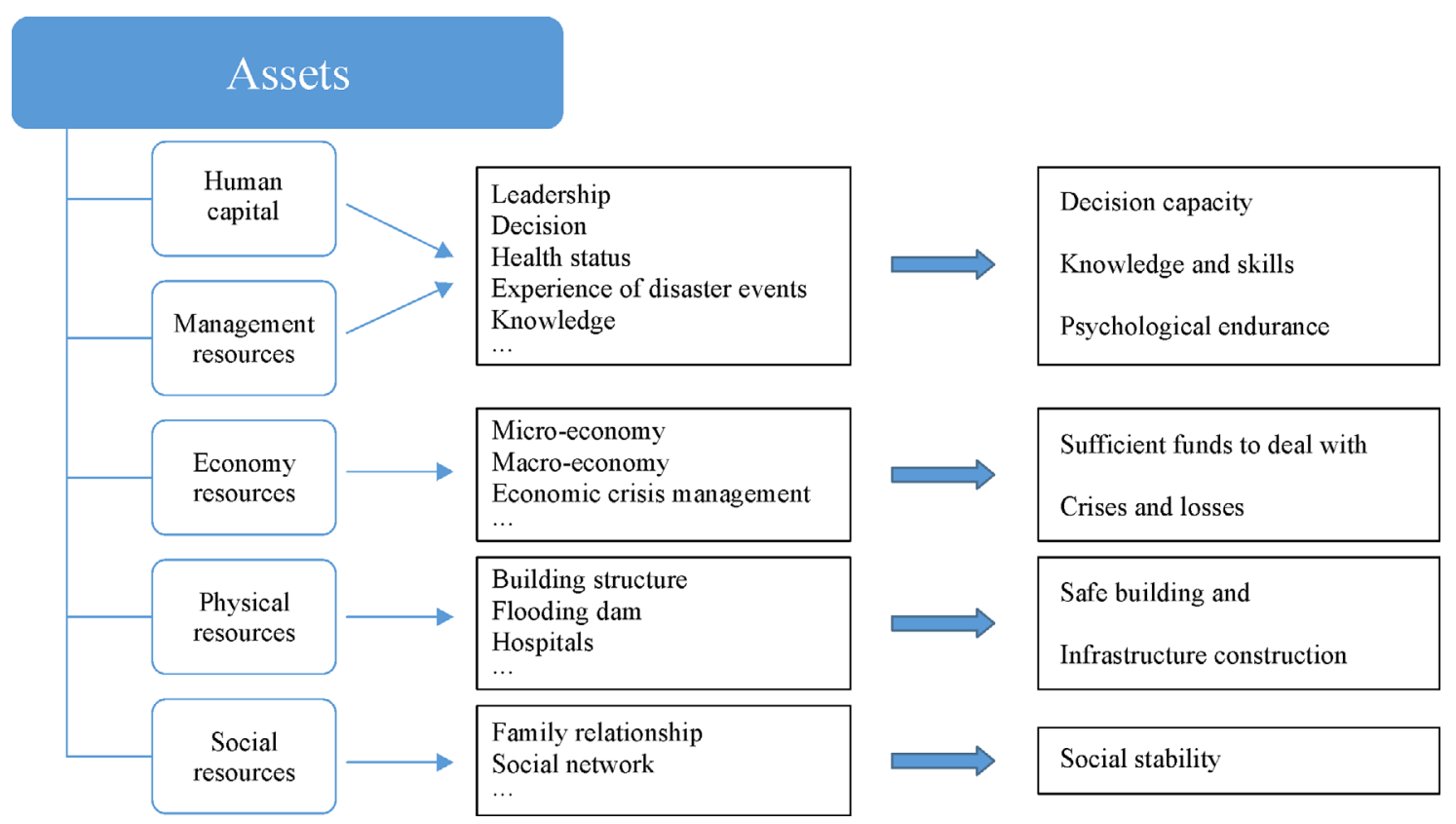

Fig. 3 Constituents of community resilience 
perception of people plays a crucial role in the establishment of community resilience. They demonstrate the method of improving the resilience of people within the framework of community resilience and emphasize the effects of human behaviors on the formation of resilience. Combined with the 4R principle of Rockefeller 100RC (Spaans and Waterhout, 2017), we believe people should be the core of city and community resilience. Behaviors of people can boost or restrain the establishment of resilience directly or indirectly. The right behaviors of human beings can promote the absorption capacity of systems to the external disturbance. Such behaviors can also accelerate the recovery of systems. By contrast, the wrong behaviors of human beings increase the stress on systems and augment the disturbance. Figure 4 shows such condition.

At present, some government agencies have appealed for greater resilience among citizens, which has been considered as better preparation before disaster. Such resilience also balances social and personal vulnerability. This balance adds to the keen interest of academics and policy makers in the practice of coping with the resilience of individuals and communities (Abramson et al., 2015). In 2011, the US Centers for Disease Control and Prevention required each state and local health department should improve the construction of community resilience and include it as one of the 15 public health emergency preparedness capabilities (Centers for Disease Control and Prevention, 2013).

When people experience misfortune, such as loss of loved ones, normal life in their cognition ends and this period lasts for a while. They may become distracted, depressed, or angry. During working or interpersonal communication, they may evidently reflect the decline in ability and reveal emotional collapse (Aloudat and Christensen, 2012). After suffering misfortune, most people can "recover", come out of disasters or misfortunes, and change their view of the world. Functions of the body recover to the normal level, including the meaning, hope, and expectation of life. However, the recovery takes a while, and the unfortunate memory lasts long. People no longer suffer because they have adapted to the existence of pain (Alshehri et al., 2015b).

This process deals with personal crises or disasters. A smart explanation for "recovery" is resilience (Smith and Stirling, 2010), which is a positive mindset and high-level human function (Manyena et al., 2011). This interpretation has been applied to individual and crowd studies, such as ecosystems and human systems.

Finally, people who lost their homes in a disaster often want to rebuild their new homes in the same place without considering the possibility of the same danger from recurring (Oliver-Smith, 1986; Vale and Campanella, 2005). People must live where they are familiar. For them, this factor is a part of community resilience.

In previous studies on community resilience, reconstruction was found to be equivalent to recovery, which is an erroneous recognition. In the reconstruction process, we focus on rebuilding infrastructure but do not consider how individuals, families, communities, and the entire social network should be repaired. Should people be afraid of rain

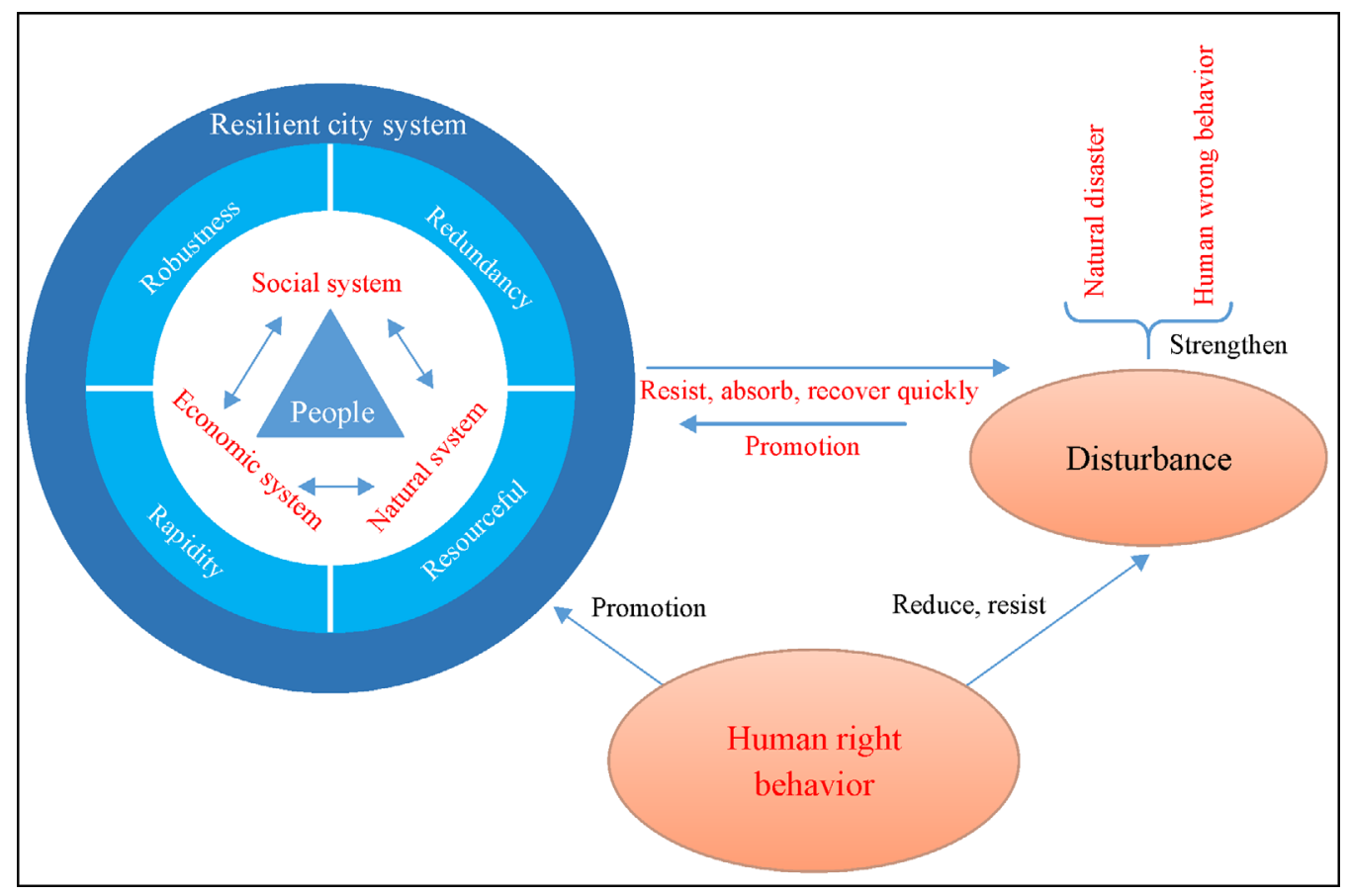

Fig. 4 Relationship between crowd and resilience community (adapted from Campanella, 2006; Norris et al., 2008; Ranjan and Abenayake, 2014; Spaans and Waterhout, 2017) 
every time after experiencing a flood? Do people buy new insurance? When loved ones die from a disaster, what does "recovery" mean to survivors? The answers to these questions often differ because of various social classes, gender, and age (Boano and Martén, 2013; Simpson, 2014).

Hurricane Katrina's case shows that about one-third of New Orleans' population has never returned to their homeland after evacuation. Most people who did not return were poor people. Meanwhile, certain wealthier residents decided not to return, but they have the power and the resources to make their own decisions. Such situation manifests individual resilience. However, when many people do not have similar choice rights, the society can hardly be described as "resilient," even if all the infrastructure is updated (Morris, 2008). Thus, one of the biggest challenges to community resilience is how to help those who have lost their homes for a long time or permanently because of a disaster. Another challenge is to rebuild emotional and other aspects of mental health (Long, 2011).

We can conclude that the basic challenges to community resilience depend on the behaviors of individuals and families in daily life that lead to disaster. Building resilient communities should begin with how individuals and families utilize the resources they already own (including knowledge and assets).

Community resistance to disasters neither means maintaining the status quo nor a hundred percent change. It means sustaining, long-term improvement, and constant changes to different scales. Community resilience provides people with access to choices and resources to help themselves do good, be good, and maintain good living conditions. This condition manifests community resilience in a long and sustainable process. Community resilience cannot exist without human beings because people are the core of the operation of the whole city system. Moreover, people hold the mobilization function of social resources, which can effectively drive the emergence of community resilience. How do we link people's functions to community resilience? Only by properly integrating human research into resilient communities can communities become truly resilient. Through literature analysis, research in this area has been found to be limited and unsystematic. Most studies emphasize the importance of resilience but no researcher has systematically analyzed the impact of urban people on the resilience of urban construction. In the context of building resilient cities, the ways and means to explore the role and function of people are not discussed. We believe that this gap is the key point for a breakthrough in community resilience construction.

\subsection{Community resilience and infrastructure construction}

Infrastructure resilience is becoming increasingly impor- tant with the onset of climate change and growing urbanization. Infrastructure assets are not only important financial investments but also provide basic social value. Despite the urgent need to build resilient infrastructure, resilience remains abstract and presents many challenges in implementation. The resilience of infrastructure includes the ability to restore the building environment from disruptive events (Vugrin et al., 2010).

Building resilience can be considered as a component of community resilience. Other infrastructure systems, such as water or power systems, can span communities or regions. The establishment of infrastructure has become an independent analytical unit because of the lack of social background. For example, Cutter found that five of the 27 resilience assessments used independent infrastructure as the unit of analysis (Cutter, 2016). Approximately $37 \%$ of the research are at the infrastructure level (such as water and power system), $35 \%$ are at the community (such as city or village), $23 \%$ are at the national, $9 \%$ are at the regional, (such as state), 6\% are at the organizational (such as corporation or emergency management agency), and 3\% are at the family level.

Studies and regional events focused on the resilience of infrastructure are summarized as follows: most studies in North America are concentrated in the United States and several studies have also been conducted in the Caribbean or Central American countries (Silva et al., 2014; Taramelli et al., 2015). Certain studies have examined several hurricanes and earthquakes in the United States (Reed et al., 2010) such as the Haiti earthquake in 2010 (Comfort et al., 2011) as well as the volcanic activity and drought in Mexico (Gavilanes-Ruiz et al., 2009; Romero, 2010). Studies in Europe (Ward and Paulus, 2013; Baubion, 2015) have usually focused on flood control in different countries. Asian research commonly occurs in China (Miao et al., 2014), Indonesia (Kusumastuti et al., 2014), and Japan (Cimellaro et al., 2014). The main concerns of these studies are China's snow disaster in 2008, the Indian Ocean tsunami in 2004, and the Tohoku earthquake and tsunami in 2011. Australian and New Zealand studies focus on the Christchurch earthquake in 2011 (MacAskill and Guthrie, 2015). Research in Africa and the Middle East is focused on heat waves and earthquake disasters, mainly in Turkey and South Africa (Harte et al., 2009; Orhan, 2014). South American studies are concentrated in Chile's earthquake (Comerio, 2014).

Infrastructure resilience at the community level is noteworthy. Community studies create opportunities for establishing resilience while certain limits exist. For example, in communities where the structure is not tight, studies at family level contain new cognition of resilience. Moreover, community studies are subject to different constraints. Some are based on geographical and political boundaries, others are based on social or family networks. The different ways of defining communities make cross case comparison research challenging. At the infrastructure 
level, only $9 \%$ of studies focus on regional linkages, such as the analysis of regional transportation network (Freiria et al., 2015), regional utilities services (Cimellaro et al., 2014), and early warning system connection (Zia and Wagner, 2015). Community is a complex social and economic communication network, located in the regional and national environment, which deserves further study.

From the literature analysis, studies on infrastructure resilience are concentrated mainly in infrastructure in specific events, such as flood dam, buildings in earthquake, and metro construction with near-miss accident. Interevent time series are analyzed in the construction industry and different domains to provide an improvement in quantitative understanding of near-miss accident phenomena. Such phenomena explain present configurations or predict future ones of near-miss network (Zhou et al., 2017). This research provides valuable and systematical contribution to the resilience construction of infrastructure. The perspective of "system of system" is a breakthrough of studies on infrastructure resilience. The current research mainly focuses on large-scale infrastructure. Thus, we should pay attention to the small scale, relatively compact space infrastructure, such as household level research.

\subsection{Community resilience and social economy}

Wein believed economic resilience refers to the resilience applied to economic activities, including "input and output," "supply and demand," "inherent and adaptive ability," and "economic level" (Wein and Rose, 2011). Rose and Chang proposed that economy resilience can be applied at three different levels that are as follows (Rose, 2009; Chang and Rose, 2012):

- micro-economy: behavior of individuals, enterprises, families, or organizations;

- med-economy: economic compositions, independent markets, cooperation groups; and

- macro-economy: integration of organizations and markets, including the interaction effect.

The social and economic development is a smooth and gradual process. However, it can be affected by various interference and destruction, such as cyclical recession, closure of factories, technical challenges from the external environment, and other disasters. The regional and local economies that confront and adjust to these disturbances affect their development and evolution. Therefore, the concept of "resilience" is also related closely to the process and mode of economic development imbalance (Simmie and Martin, 2010). If the concept of resilience can be established based on the ability to adapt to economies, then regional or local economic regulations and control capabilities can be identified effectively.

The concept of engineering resilience is related closely to the standard equilibrium concept in mainstream economics. A shock or disturbance deviates economies away from their growth path. However, such disturbance can eventually bring economies back to their original growth path with their self-correcting forces and regulatory capabilities. Regional economies with resilience should be adaptive economies. After the shock, such economies can be restored successfully to their long-term balanced growth path. They may even become better than before. Regional economies without resilience cannot change themselves after the impact. They are "stuck" in the old structure, and their long-term production capacity in an imbalanced growth path reduces correspondingly. Therefore, theory of resilience is also applicable to economic construction, and community resilience should include economic resilience.

In the current study, certain scholars expounded the importance of economic resilience, given the corresponding concept. Moreover, relevant research such as the level of economic resilience and self-adaptive economy are also launched. However, these studies are still in a relatively independent status. Integrating economic resilience with community resilience system is an inevitable trend. Moreover, current research of economic resilience is limited to recovering quickly after economic crises. Such recovery is a unilateral understanding of resilience. The whole process model should be one of the focuses in future research such as, insurance plans before disasters, rapid settlement of claims after disasters, reconstruction of capital system, and the establishment of the mechanism of economic resilience.

\subsection{Community resilience and social resources}

In the frame of community resilience, social resources focus on people in the community. For example, Sandler and Wolchik stated that many social resources are beneficial to students regardless of current risks and levels of stress (Sandler and Wolchik, 1997). Social/community environmental resources are powerful media for mental health of individuals after disasters. Well-integrated and reasonably utilized resources may manifest the attributes of community resilience (Murray et al., 2000).

Before disasters, the potential resilience properties of communities include population health (human capital) and density; formal/informal social network and community information connectivity (social capital); mitigation and insurance strategies, which are used widely to identify and avoid social risks (economic capital); work efficiency of local governments with social consensus; and fair allocation and management of public resources (political capital) (Murray et al., 2000).

In the post-disaster phase, activating community resilience attributes may include the following.

- The establishment of high-quality medical and mental health systems (human capital);

- The development and utilization of emergency mechanisms to facilitate access to social networks, or integrate trustworthy community organizations and networks (social capital); 
- The establishment of fairness-oriented process of public discussion and collective action (political capital);

- The ability to obtain and distribute public and private funds (economic capital) (Dumont and Provost, 1999; Adger, 2000).

Abramson et al. (2015) discussed the resilience attributes at individual and community levels. A resilience activation model is developed to explain that public health behaviors in crises arise from the effective connection between resilient individuals and social resources. The model still requires further discussion on how the connection model is established.

Paton (2007) suggested a new point of view from the angle of individuals, communities, and institutions. Under every headline, disasters bring destruction and loss. A series of characteristics and abilities is necessary to maintain "leaping forward." All kinds of "resources" mean the great demand for capacity recovery after disasters and the extreme desire for balancing the distribution of resources. Institutions, which are the most dependent on individuals and communities, are the most vulnerable to disasters. Once disasters strike, new institutions can easily replace old ones through humanitarian aid. The processes and cultures of new institutions differ those of the past (Folke, 2006).

Through literature analysis, we can draw upon social resource as a key factor in the construction of community resilience. Such factor is also relevant to all aspects of human beings in communities, such as population structure, health, policy, infrastructure and availability, and economic level. Therefore, we believe to improve community resilience, improving social factors effectively and efficiently, such as education, employment, and population health is necessary. A universal consensus that social resource is important to the construction of community resilience exists. Certain scholars believe community resilience can be considered as the ability of individuals related to critical social resources. However, further studies are necessary to clarify how this ability will be measured. Moreover, how social resources with different attributes affect the construction of resilience and how their priorities are sorted can be future research directions.

\section{Community resilience assessment (CRA)}

CRA is recognized as an important step in reducing disaster risks. It helps individuals to withstand and adapt to natural and man-made disasters (Burton, 2015). The resilience assessment tools make the concept of resilience specific and measurable. These tools can be utilized to understand the meaning of community resilience. The tools also have a positive role in interpreting different environments, as well as social, economic, physical, and social systems. Moreover, considering the uncertainties of the future and providing a good understanding of the complexity of communities as a social ecosystem are encouraged (Levine, 2014; Sellberg et al., 2015). The resilience assessment tools can evaluate the practice of community peers and best practice standards through resilience status. This assessment has resulted in competition among communities and provides a platform for them to share knowledge and learn from each other (Rigby et al., 2008). When allocating limited resources, the assessment can also help identify and prioritize undeveloped areas. (Renschler et al., 2010; Sempier et al., 2010; Khazai et al., 2015).

At present, CRA tools and frameworks have focused mainly on the communities in urban environment. However, certain tools are beyond urban scale and can be used in rural communities. Therefore, when using the concept of community resilience, we should pay attention to generality and avoid distinguishing cities from rural areas.

Khazai et al. (2015) believed the post-disaster decision support system and assessment tools can be used to restore organizations and reduce disaster risks. Such system and tools can also monitor the effectiveness and efficiency of organization plans, making communities flexible and resilient. Irajifar et al. (2013) surveyed eight selected evaluation frameworks and found that the specific variables and appropriate measurement purposes at the community level were absent. Larkin et al. (2015) developed a set of measurement methods called CRA. This set of method can provide a participation platform for organizations and stakeholders in the planning and preparation process, establish effective cooperation between internal and external communities, and enable communities to cope with the challenges from society, economy, and the environment. CRA also helps create resilient "control strategies" through iterative computation, quantification, and resilience implementation frameworks. The CRA tool should be studied further to identify its shortcomings and limitations as well as clarify potential directions for improvement. Thus, communities become effective in disaster prevention planning. Monaghan et al. (2014) provided a toolkit of six CRA and explained their main features. Pfefferbaum et al. (2015) studied six different CRA tools and their similarities and differences. Results show that existing tools have achieved considerable success in promoting resilience assessment. Further studies are also necessary to provide a resilient approach to community development. To date, the most detailed survey was provided by Cutter, who outlined 27 assessment tools (Cutter, 2016). Cutter discussed the commonalities and differences between these tools from the perspective of spatial orientation, major dimensions, and assessment methods. Cutter believed the existence of multiple solutions for assessment can be interpreted as different motivations of evaluators, considering different backgrounds. Cutter also emphasized the need for a multi- 
discipline design of evaluation tools. The importance of cognition in the role of community social vitality is also discussed in the evaluation.

Many methods used in the study of resilience assessment apply quantitative and qualitative methods. Quantitative method was adopted from 55\% literature, 39\% with qualitative method, and $6 \%$ with mixed method. Further analysis showed that $31 \%$ of the studies were conducted through simulation or other modeling techniques, $24 \%$ proposed theoretical frameworks, $15 \%$ used geographic information system (GIS), 9\% used literature analysis, 7\% with questionnaire survey, $7 \%$ with expert suggestions, and $4 \%$ used network analysis.

The most commonly used method is modeling, which includes economic analysis (Resurreccion and Santos, 2013), operational infrastructure (Jonkeren and Giannopoulos, 2014), recovery time (Luna et al., 2011), and ability (Ouyang and Wang, 2015). GIS reveals risks based on the spatial relationship, the application of which in recent years rises sharply (since 2010, an annual increase of $10 \%$ in the literature). GIS has become the third ranking research method (Armenakis and Nirupama, 2013).

Many studies take advantage of quantitative modeling by using early research to begin quantifying resilience studies, especially common economic resilience (Armas, 2012). Few qualitative studies exist. However, these studies sometimes challenge the assumptions of modeling, or direct against communities, governments, and stakeholders who do not comply with social norms, laws, and regulations (Grove, 2014). For example, certain communities ignore the governmental relocation plan and decide to stay in a dangerous place for financial reasons. Therefore, qualitative case studies are necessary to show the examples of recovery after catastrophic events and validate the results through simulation modeling. Discovering new results from qualitative research as well as new behaviors of individuals, organizations, and institutions is necessary.

By summarizing the literature, several current measurement tools of community resilience such as qualitative and quantitative methods, application of regulations and GIS, description of paradigms, and the quantitative calculation of recovery time are drawn. However, an effective assessment tool should provide a comprehensive solution to the multiple dimensions of community resilience, consider the relationship between different spatial scales, become capable of measuring changes in timeline, develop appropriate measures to capture uncertain factors, formulate and implement resilience improvement strategies for stakeholders, and carry out action plans. Therefore, we must focus on the applicability and operability of measurement tools in applying resilience measurement in future research. After all, measurement methods may differ but no absolutely good or bad tool exists. In studying new assessment methods in the future, cross discipline should be important. The measurement should combine the new technology and methods of different fields into the study of resilience. Improving the index system of measurement is also crucial to improve the accuracy and measuring speed of resilience measurement.

\section{Problems and challenges}

Any community is composed of many heterogeneous subgroups. People are stratified according to different decision, capacity, and vulnerability levels, wealth, income, moral standards, and religious status, in accordance with gender, age, nationality, and ability. No matter what kind of community stratification is adopted, beneficiaries and victims before and after disasters always exist. Humanitarian aid, recovery, and reconstruction help communities to return to their original state. Instead of building new communities, the general sense of resilience is returning to "normal" state before disasters. We usually take the banner of "Going back to a better past" to solve the problems that cause disasters. Returning to the original state only maintains communities at the same fragility level (before disasters occurred), or even promotes vulnerability level (as it suffered once), whereas the productivity and resilience of communities are reduced. However, communities unaffected by disasters are improving their energy supply capacity, productivity, and community resilience constantly (Susman et al., 1983).

Risk is the intersection of hazard and vulnerability (Wisner et al., 2012; Blake, 2014). When communities return to their "normal" state (before disasters occurred), increasing the vulnerability and not reducing the hazard are parts of the risk-increasing process. Therefore, a narrow sense of understanding of community resilience may lead to an increase in community risk (Wisner et al., 2012).

In community resilience studies, the overall effect is greater than the partial additivity. The resilience of individuals does not represent the resilience of communities (Brown and Kulig, 1996; Chang and Rose, 2012). Hence, to create a collective resilience, communities must reduce the risk and resource inequality, promote residents to join risk mitigation activities, establish organizations, promote and protect social support, and make new action plans. These factors require communities to have flexible decision-making tools and credible sources of information in the case of uncertain catastrophes.

Community resilience focuses not only on disasters (or "events" or "disturbances") on a specific space and time but also with common effects caused by various risks with multiple vulnerability and interactions.

At present, the study of community resilience focuses on two aspects:

- Prevention of disaster-related physical and mental health problems of community members by constructing community resilience; and

- Establishment of effective organizational behaviors 
and disaster management models through the study of community resilience (Norris et al., 2008).

By analyzing these two aspects, the object of community resilience was found to be the people who live in it. The purpose is to improve the quality of life by constructing community resilience. Therefore, how does community resilience improve through the resilience of the crowd and form a virtuous circle? Can we develop an effective theoretical system and methodology for building resilience among people, such as the evaluation system of collective resilience? Moreover, the current study of community resilience is still relatively independent. Analyzing community resilience at the system level requires further development.

\section{Conclusions}

Based on a holistic review of existing literature, this study summarizes important issues and progress in community resilience research through a comprehensive analysis of community, resilience, and community resilience. The study uses literature review from the past decade, standing on the shoulders of giants, taking the connotation, attribute, composition, and assessment of community resilience as breakthrough points. Thus, we put forward the challenges and deficiencies faced by the construction of community resilience. Moreover, the research directions on the following aspects, which should be paid attention to in the future, are proposed.

- Develop an integrated concept of community resilience. Building community resilience with multidisciplinary integration is significant in the development of the comprehensive concept of community resilience and to grasp the core contents of community resilience research.

- Focus on the resilience building of less developed economic areas. Through literature cases, we found most studies aim at the economically developed regions. Concern for the less developed areas (but with population density and high disaster frequency) is lacking.

- New elements of resilience should be focused on to explore the cross-disciplinary attribute of resilience. Community resilience is an interdisciplinary research field involving many subjects in natural and social sciences. In future research, we should interpret the characteristics and advantages of interdisciplinary studies, apply innovative methods to the study of community resilience, and apply additional cross methods to understand cross-dimensional resilience.

- Study the infrastructure construction within the framework of society. Past works have isolated the infrastructure and environment construction from society. However, the connection between the two sections is crucial to the improvement of the contribution of the building environment to community resilience.

- Emphasize on the public dimension of community resilience. At present, many studies on community resilience refer to the importance of the public. However, studies involving collective and public resilience are still limited in the field of psychology. Moreover, the study of community resilience has not gained substantive progress. Selecting a proper method to integrate the resilience of public and people into community is critical.

- Apply new technologies in the evaluation and measurement of community resilience. At present, the methods of evaluation and measurement on community resilience are diverse. In the future, new technologies and methods, such as big data technology, should be combined into resilience to improve the accuracy and speed of measurement.

We hope to clarify the status quo of community resilience research and grasp the future research priorities. We believe the future of community resilience should emphasize the perspective of "system of system," and build on knowledge and tools of various relevant domains, and consider the public needs and participation. Moreover, infrastructure and economic resilience, social resource allocation, network connection, and other aspects of social construction should be integrated. Our next research aims to establish a resilient community with integrity.

Acknowledgements The authors are grateful for the support of the Ministry of Science and Technology (MOST) of China, Ministry of Education of China (MOE), National Natural Science Foundation of China (NSFC) and Tsinghua University. Any opinions, findings, and conclusions or recommendations expressed in this paper are those of the authors and do not necessarily reflect the views of the funding agencies.

\section{References}

Abramson D M, Grattan L M, Mayer B, Colten C E, Arosemena F A, Bedimo-Rung A, Lichtveld M (2015). The resilience activation framework: A conceptual model of how access to social resources promotes adaptation and rapid recovery in post-disaster settings. Journal of Behavioral Health Services \& Research, 42(1): 42-57

Adger W N (2000). Social and ecological resilience: Are they related? Progress in Human Geography, 24(3): 347-364

Adger W N (2003). Social capital, collective action, and adaptation to climate change. Economic Geography, 79(4): 387-404

Adger W N (2006). Vulnerability. Global Environmental Change, 16(3): 268-281

Agrawal A, Gibson C C (1999). Enchantment and disenchantment: The role of community in natural resource conservation. World Development, 27(4): 629-649

Ahmed R, Seedat M, Van Niekerk A, Bulbulia S (2004). Discerning community resilience in disadvantaged communities in the context of violence and injury prevention. South African Journal of Psychology, 34(3): 386-408

Allen K M (2006). Community-based disaster preparedness and climate adaptation: Local capacity-building in the Philippines. Disasters, 30 (1): $81-101$

Aloudat T, Christensen L (2012). The Routledge Handbook of Hazards and Disaster Risk Reduction. London: Routledge 
Alshehri S A, Rezgui Y, Li H (2015a). Disaster community resilience assessment method: A consensus-based Delphi and AHP approach. Natural Hazards, 78(1): 395-416

Alshehri S A, Rezgui Y, Li H (2015b). Delphi-based consensus study into a framework of community resilience to disaster. Natural Hazards, 75(3): 2221-2245

Armaş I (2012). Multi-criteria vulnerability analysis to earthquake hazard of Bucharest, Romania. Natural Hazards, 63(2): 1129-1156

Armenakis C, Nirupama N (2013). Prioritization of disaster risk in a community using GIS. Natural Hazards, 66(1): 15-29

Baubion C (2015). Losing memory-the risk of a major flood in the Paris region: Improving prevention policies. Water Policy, 17(S1): 156179

Bell C, Newby H (1973). Community Studies: An Introduction to the Sociology of the Local Community. New York: Praeger

Blake P, Cannon T, Davis I, Wisner B (2014). At risk: Natural Hazards, People's Vulnerability and Disasters. London: Routledge

Boano C, Martén R (2013). Agamben's urbanism of exception: Jerusalem's border mechanics and biopolitical strongholds. Cities, 34: $6-17$

Bodin P, Wiman B (2004). Resilience and other stability concepts in ecology: Notes on their origin, validity, and usefulness. ESS Bulletin, 2(2): $33-43$

Bonanno G A, Galea S, Bucciarelli A, Vlahov D (2006). Psychological resilience after disaster: New York City in the aftermath of the September 11th terrorist attack. Psychological Science, 17(3): 181186

Brand F, Jax K (2007). Focusing the meaning(s) of resilience: Resilience as a descriptive concept and a boundary object. Ecology and Society, 12(1): 181-194

Brown D D, Kulig J C (1996). The concepts of resiliency: Theoretical lessons from community research. Health and Canadian Society, 4: $29-50$

Burton C G (2015). A validation of metrics for community resilience to natural hazards and disasters using the recovery from Hurricane Katrina as a case study. Annals of the Association of American Geographers, 105(1): 67-86

Butler L, Morland L, Leskin G (2007). Psychological resilience in the face of terrorism. Psychology of Terrorism, 400: 417

Campanella T J (2006). Urban resilience and the recovery of New Orleans. Journal of the American Planning Association, 72(2): 141146

Carpenter S, Walker B, Anderies J M, Abel N (2001). From metaphor to measurement: resilience of what to what? Ecosystems, 4(8): 765781

Centers for Disease Control and Prevention (2013). Public health preparedness capabilities: National standards for state and local planning. https://www.cdc.gov/phpr/readiness/capabilities.htm, 2017-12-28

Chang S E, Rose A Z (2012). Towards a theory of economic recovery from disasters. International Journal of Mass Emergencies and Disasters, 30(2): 171-181

Chaskin R J (2008). Resilience, community, and resilient communities: Conditioning contexts and collective action. Child Care in Practice, 14(1): 65-74

Checkland P (2000). Soft systems methodology: A thirty year retrospective. Systems Research and Behavioral Science, 17(S1): S11-S58

Cimellaro G P, Solari D, Bruneau M (2014). Physical infrastructure interdependency and regional resilience index after the 2011 Tohoku earthquake in Japan. Earthquake Engineering \& Structural Dynamics, 43(12): 1763-1784

Colten C E, Kates R W, Laska S B (2008). Community resilience: Lessons from new Orleans and hurricane Katrina. CARRI Report, 3

Comerio M C (2014). Housing recovery lessons from Chile. Journal of the American Planning Association, 80(4): 340-350

Comfort L K, McAdoo B, Sweeney P, Stebbins S, Siciliano M D, Huggins L J, Serrant T, Scheinert S, Augenstein J, Krenitsky N (2011). Transition from response to recovery: A knowledge commons to support decision making following the 12 January 2010 Haiti Earthquake. Earthquake Spectra, 27(S1): S411-S430

Cowen E L (2001). The use and misuse of some positively valenced community concepts. Community Mental Health Journal, 37(1): 313

Cutter S L (2016). The landscape of disaster resilience indicators in the USA. Natural Hazards, 80(2): 741-758

Cutter S L, Barnes L, Berry M, Burton C, Evans E, Tate E, Webb J (2008). A place-based model for understanding community resilience to natural disasters. Global Environmental Change, 18(4): 598-606

Davoudi S, Shaw K, Haider L J (2012). Resilience: A bridging concept or a dead end? "Reframing" resilience: Challenges for planning theory and practice interacting traps: Resilience assessment of a pasture management system in Northern Afghanistan urban resilience: What does it mean in planning practice? Resilience as a useful concept for climate change adaptation? The politics of resilience for planning: A cautionary note: edited by Simin Davoudi and Libby Porter. Planning Theory \& Practice, 13(2): 299-333

Dominelli L (2012). Green Social Work: From Environmental Crises to Environmental Justice. Cambridge: Polity

Dovers S R, Handmer J W (1992). Uncertainty, sustainability and change. Global Environmental Change, 2(4): 262-276

Dumont M, Provost M A (1999). Resilience in adolescents: Protective role of social support, coping strategies, self-esteem, and social activities on experience of stress and depression. Journal of Youth and Adolescence, 28(3): 343-363

Dynes R R (1998). What is a Disaster. London: Routledge

Earvolino-Ramirez M (2007). Resilience: a concept analysis. Nursing Forum, 42(2): 73-82

Fellin P (2001). The Community and the Social Worker. Pacific Grove: Brooks/Cole Publishing Company

Flora J L (1998). Social capital and communities of place. Rural Sociology, 63(4): 481-506

Folke C (2006). Resilience: The emergence of a perspective for socialecological systems analyses. Global Environmental Change, 16(3): 253-267

Freiria S, Tavares A O, Pedro Julião R (2015). The multiscale importance of road segments in a network disruption scenario: a risk-based approach. Risk Analysis, 35(3): 484-500

Gaillard J C (2007). Resilience of traditional societies in facing natural hazards. Disaster Prevention and Management: An International Journal, 16(4): 522-544

Gavilanes-Ruiz J C, Cuevas-Muñiz A, Varley N, Gwynne G, Stevenson 
J, Saucedo-Girón R, Pérez-Pérez A, Aboukhalil M, Cortés-Cortés A (2009). Exploring the factors that influence the perception of risk: The case of Volcán de Colima, Mexico. Journal of Volcanology and Geothermal Research, 186(3-4): 238-252

Godschalk D R (2003). Urban hazard mitigation: creating resilient cities. Natural Hazards Review, 4(3): 136-143

Gordon J E (1978). Structures. Harmondsworth: Penguin

Grove K (2014a). Agency, affect, and the immunological politics of disaster resilience. Environment and Planning. D, Society \& Space, 32(2): 240-256

Handmer J W, Dovers S, Downing T E (1999). Societal vulnerability to climate change and variability. Mitigation and Adaptation Strategies for Global Change, 4(3-4): 267-281

Handmer J W, Dovers S R (1996). A typology of resilience: Rethinking institutions for sustainable development. Industrial \& Environmental Crisis Quarterly, 9(4): 482-511

Harte E W, Childs I R, Hastings P A (2009). Imizamo Yethu: A case study of community resilience to fire hazard in an informal settlement Cape Town, South Africa. Geographical Research, 47(2): 142-154

Holling C S (1973). Resilience and stability of ecological systems. Annual Review of Ecology and Systematics, 4(1): 1-23

IFRC (2015). World Disasters Report 2015. http://ifrc-media.org/ interactive/world-disasters-report-2015/

Irajifar L, Alizadeh T, Sipe N (2013). Disaster resiliency measurement frameworks: State of the art. In: Proceedings of World Building Congress. Brisbane

Islam M S (2014). Confronting the Blue Revolution: Industrial Aquaculture and Sustainability in the Global South. Toronto: University of Toronto Press

Islam M S, Quek R A (2014). Globalization, Development and Security in Asia: Environment and Sustainable Development in Asia. Singapore: WSPC

Jonkeren O, Giannopoulos G (2014). Analysing critical infrastructure failure with a resilience inoperability input-output model. Economic Systems Research, 26(1): 39-59

Kais S M, Islam M S (2016). Community capitals as community resilience to climate change: Conceptual connections. International Journal of Environmental Research and Public Health, 13(12): 1211

Kelly E C, Bliss J C (2009). Healthy forests, healthy communities: An emerging paradigm for natural resource-dependent communities? Society \& Natural Resources, 22(6): 519-537

Khazai B, Bendimerad F, Cardona O D, Carreño M L, Barbat A H, Buton C G (2015). A guide to measuring urban risk resilience: Principles, tools and practice of urban indicators. Earthquakes and Megacities Initiative (EMI), The Philippines

Khew Y T J, Jarzebski M P, Dyah F, San Carlos R, Gu J, Esteban M, Aránguiz R, Akiyama T (2015). Assessment of social perception on the contribution of hard-infrastructure for tsunami mitigation to coastal community resilience after the 2010 tsunami: Greater Concepcion area, Chile. International Journal of Disaster Risk Reduction, 13: 324-333

Klein A M, Steffan-Dewenter I, Tscharntke T (2003). Fruit set of highland coffee increases with the diversity of pollinating bees. Proceedings of the Royal Society of London. Series B, Biological Sciences, 270(1518): 955-961

Kulig J C (2000). Community resiliency: The potential for community health nursing theory development. Boston: Public Health Nursing, 17(5): 374-385

Kumaraswamy M, Wong K K W, Chung J (2017). Focusing megaproject strategies on sustainable best value of stakeholders. Built Environment Project and Asset Management, 7(4): 441-455

Kusumastuti R D, Viverita, Husodo Z A, Suardi L, Danarsari D N (2014). Developing a resilience index towards natural disasters in Indonesia. International Journal of Disaster Risk Reduction, 10: 327340

Larkin S, Fox-Lent C, Eisenberg D A, Trump B D, Wallace S, Chadderton C, Linkov I (2015). Benchmarking agency and organizational practices in resilience decision making. Environment Systems \& Decisions, 35(2): 185-195

Levine S (2014). Assessing resilience: Why quantification misses the point. Humanitarian Policy Group (ODI) Working Paper

Long H L (2011). Disaster prevention and management: A geographical perspective. Disaster Advances, 4(1): 3-5

Luna J, Ghani H, Germanus D, Suri N (2011). A security metrics framework for the cloud. In: Proceedings of the International Conference on Security and Cryptography (SECRYPT). IEEE: 245-250

MacAskill K, Guthrie P (2015). A hierarchy of measures for infrastructure resilience-learning from post-disaster reconstruction in Christchurch, New Zealand. Civil Engineering and Environmental Systems, 32(1-2): 130-142

Manyena B, O’Brien G, O'Keefe P, Rose J (2011). Disaster resilience: A bounce back or bounce forward ability? Local Environment. International Journal of Justice and Sustainability, 16(5): 417-424

Manyena S B (2006). The concept of resilience revisited. Disasters, 30 (4): 434-450

Matthews P H (2014). The Concise Oxford Dictionary of Linguistics. Oxford: Oxford University Press

McCrea R, Walton A, Leonard R (2014). A conceptual framework for investigating community wellbeing and resilience. Rural Society, 23 (3): $270-282$

Miao X, Tang Y, Xi B (2014). The role of coupling and embeddedness in risk evolution: Rethinking the snow event in early 2008, China. Natural Hazards, 71(1): 53-61

Mohan G, Stokke K (2000). Participatory development and empowerment: The dangers of localism. Third World Quarterly, 21(2): 247268

Monaghan P, Ott E, Fogarty T (2014). Measuring Community Resilience using Online Toolkits. The Institute of Food and Agricultural Sciences Extension Service and University of Florida

Morris J E (2008). Out of New Orleans: Race, class, and researching the Katrina diaspora. Urban Education, 43(4): 463-487

Murphy B L (2007). Locating social capital in resilient community-level emergency management. Natural Hazards, 41(2): 297-315

Murray Nettles S, Mucherah W, Jones D S (2000). Understanding resilience: The role of social resources. Journal of Education for Students Placed at Risk, 5(1-2): 47-60

Neil J (2015). What is psychological resilience? http://www.wilderdom. com/psychology/resilience/PsychologicalResilience.html, 2015-629

Norris F H, Stevens S P, Pfefferbaum B, Wyche K F, Pfefferbaum R L (2008). Community resilience as a metaphor, theory, set of capacities, 
and strategy for disaster readiness. American Journal of Community Psychology, 41(1-2): 127-150

Oliver-Smith A (1986). Natural disasters and cultural responses. Department of Anthropology, College of William and Mary

Orhan E (2014). The role of lifeline losses in business continuity in the case of Adapazari, Turkey. Environmental Hazards, 13(4): 298312

Ouyang M, Wang Z (2015). Resilience assessment of interdependent infrastructure systems: With a focus on joint restoration modeling and analysis. Reliability Engineering \& System Safety, 141: 74-82

Paton D (2007). Measuring and monitoring resilience in Auckland. Wellington: GNS Science

Pfefferbaum B, Pfefferbaum R L, Van Horn R L (2015). Community resilience interventions: Participatory, assessment-based, actionoriented processes. American Behavioral Scientist, 59(2): 238-253

Pfefferbaum B J, Devoe E R, Stuber J, Schiff M, Klein T P, Fairbrother $G$ (2005). Psychological impact of terrorism on children and families in the United States. Journal of Aggression, Maltreatment \& Trauma, 9(3-4): 305-317

Pfefferbaum B J, Reissman D B, Pfefferbaum R L, Klomp R, Gurwitch R (2008). In: Doll L, Bonzo S, Sleet D, Mercy J, eds. Handbook of Injury and Violence Prevention. Boston: Springer

Ranjan E S, Abenayake C C (2014). A study on community's perception on disaster resilience concept. Procedia Economics and Finance, 18: 88-94

Reed D A, Powell M D, Westerman J M (2010). Energy infrastructure damage analysis for hurricane Rita. Natural Hazards Review, 11(3): 102-109

Reid R, Botterill L C (2013). The multiple meanings of 'resilience': An overview of the literature. Australian Journal of Public Administration, 72(1): 31-40

Renschler C S, Frazier A E, Arendt L A, Cimellaro G P, Reinhorn A M, Bruneau M (2010). A Framework for Defining and Measuring Resilience at the Community Scale: The PEOPLES Resilience Frame Work. Buffalo: MCEER

Resurreccion J Z, Santos J R (2013). Uncertainty modeling of hurricanebased disruptions to interdependent economic and infrastructure systems. Natural Hazards, 69(3): 1497-1518

Rigby S A, Thornton E W, Young C A (2008). A randomized group intervention trial to enhance mood and self-efficacy in people with multiple sclerosis. British Journal of Health Psychology, 13(4): 619631

Rogers P (2013). The rigidity trap in global resilience: Neoliberalisation through principles, standards, and benchmarks. Globalizations, 10 (3): 383-395

Rogers P P, Jalal K F, Boyd J A (2012). An Introduction to Sustainable Development. London: Earthscan

Romero Lankao P (2010). Water in Mexico City: What will climate change bring to its history of water-related hazards and vulnerabilities? Environment and Urbanization, 22(1): 157-178

Rose A (2004). Defining and measuring economic resilience to disasters. Disaster Prevention and Management: An International Journal, 13 (4): $307-314$

Rose A Z (2009). Economic resilience to disasters. Disaster Prevention \& Management An International Journal, 13(4): 307-314

Rutter M (1993). Resilience: Some conceptual considerations. Journal of
Adolescent Health, 14(8): 626-631, 690-696

Sandler I N, Wolchik S A, MacKinnon D, Ayers T S, Roosa M W (1997). In: Wolchick S A, Sandler I N, eds. Handbook of Children's Coping. Boston: Springer

Satterthwaite D, Mitlin D (2013). Empowering Squatter Citizen: Local Government, Civil Society and Urban Poverty Reduction. London: Routledge

Sellberg M M, Wilkinson C, Peterson G D (2015). Resilience assessment: A useful approach to navigate urban sustainability challenges. Ecology and Society, 20(1): 43

Sempier T T, Swann D L, Emmer R, Sempier S H, Schneider M (2010). Coastal community resilience index: A community self-assessment. http://www.masgc.org/pdf/masgp/08-014.pdf, 2013-6-17

Sherrieb K, Norris F H, Galea S (2010). Measuring capacities for community resilience. Social Indicators Research, 99(2): 227-247

Silva R, Marténez M L, Hesp P A, Catalan P, Osorio A F, Martell R, Fossati M, Miot da Silva G, Mariño-Tapia I, PereiraP, CienguegosR, Klein A, Govaere G (2014). Present and future challenges of coastal erosion in Latin America. Journal of Coastal Research, 71(sp1): 1-16

Simmie J, Martin R (2010). The economic resilience of regions: towards an evolutionary approach. Cambridge Journal of Regions, Economy and Society, 3(1): 27-43

Simpson A (2014). In: Simpson A, eds. The Brand Strategist's Guide to Desire. London: Palgrave Macmillan

Smith A, Stirling A (2010). The politics of social-ecological resilience and sustainable socio-technical transitions. Ecology and Society, 15(1): 11

Sonn C C, Fisher A T (1998). Sense of community: Community resilient responses to oppression and change. Journal of Community Psychology, 26(5): 457-472

Spaans M, Waterhout B (2017). Building up resilience in cities worldwide-Rotterdam as participant in the 100 Resilient Cities Programme. Cities, 61: 109-116

Susman P, O'Keefe P, Wisner B (1983). Interpretations of Calamity. Boston: Allen \& Unwin Inc.

Taramelli A, Valentini E, Sterlacchini S (2015). A GIS-based approach for hurricane hazard and vulnerability assessment in the Cayman Islands. Ocean and Coastal Management, 108: 116-130

Turnbull M, Sterrett C L, Hilleboe A (2013). Toward Resilience: A Guide to Disaster Risk Reduction and Climate Change Adaptation. London: Practical Action Publishing

Ungar M (2011). Community resilience for youth and families: Facilitative physical and social capital in contexts of adversity. Children and Youth Services Review, 33(9): 1742-1748

UNISDR (2014). Disaster Resilience Scorecard for Cities. United Nations Office for Disaster Risk Reduction

Vale L J, Campanella T J (2005). The Resilient City: How Modern Cities Recover from Disaster. Oxford: Oxford University Press

Vugrin E D, Warren D E, Ehlen M A, Camphouse R C (2010). In: Gopalakrishnan K, Peeta S, eds. Sustainable and Resilient Critical Infrastructure Systems. Berlin: Springer

Walmsley J (2006). The nature of community: Putting community in place. Dialogue, 25(1): 5-12

Wanitkorkul A, Filiatrault A (2005). Simulation of strong ground motions for seismic fragility evaluation of nonstructural components in hospitals. Multidisciplinary Center for Earthquake Engineering 
Research, University at Buffalo, State University of New York

Ward S M, Paulus G (2013). Augmenting Austrian flood management practices through geospatial predictive analytics: A study in Carinthia. Natural Hazards and Earth System Sciences, 13(6): $1445-1455$

Wein A, Rose A (2011). Economic resilience lessons from the ShakeOut earthquake scenario. Earthquake Spectra, 27(2): 559-573

Werner E E, Smith R (1982). Vulnerable but Not Invincible: A Study of Resilient Children. New York: McGraw-Hill

Wiek A, Ness B, Schweizer-Ries P, Brand F S, Farioli F (2012). From complex systems analysis to transformational change: A comparative appraisal of sustainability science projects. Sustainability Science, 7 (1): $5-24$

Wilson G A (2012a). Community Resilience and Environmental Transitions. London: Routledge
Wilson G A (2012b). Community resilience, globalization, and transitional pathways of decision-making. Geoforum, 43(6): 12181231

Wisner B, Gaillard J C, Kelman I (2012). Handbook of Hazards and Disaster Risk Reduction and Management. London: Routledge

Wisner B, Kelman I (2015). Community Resilience to Disasters. International Encyclopedia of the Social \& Behavioral Sciences, 2 (4): 354-360

Zhou C, Ding L, Skibniewski M J, Luo H, Jiang S (2017). Characterizing time series of near-miss accidents in metro construction via complex network theory. Safety Science, 98: 145-158

Zia A, Wagner C H (2015). Mainstreaming early warning systems in development and planning processes: Multilevel implementation of Sendai framework in Indus and Sahel. International Journal of Disaster Risk Science, 6(2): 189-199 